\title{
focus on oldham
}
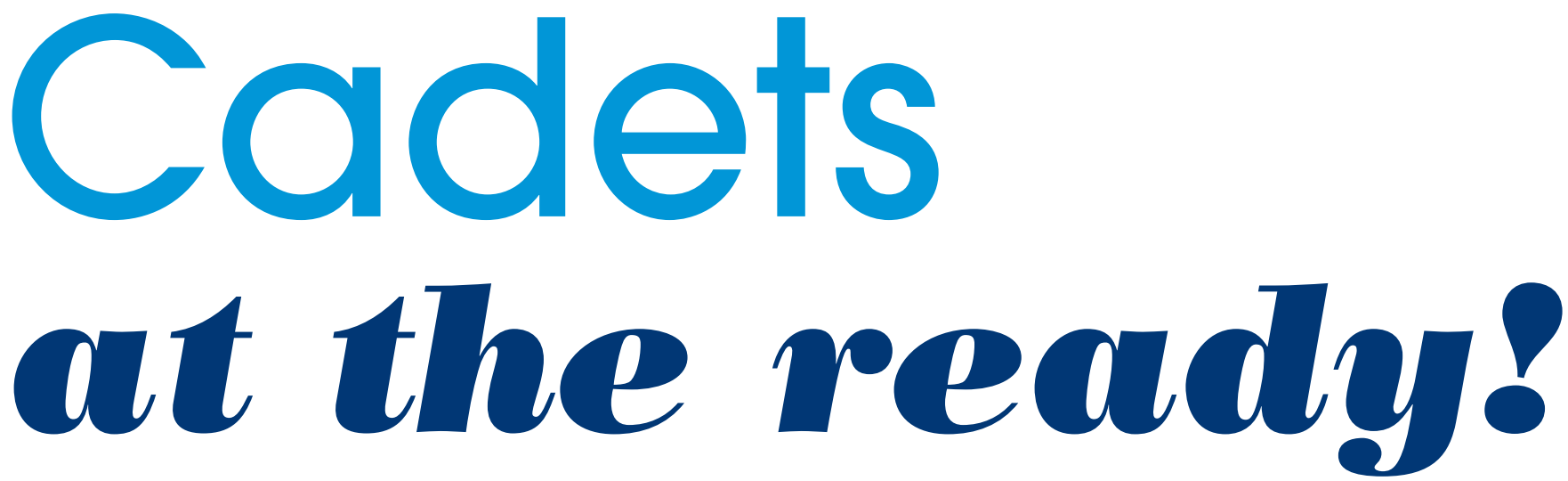

he desperate need for more NHS dentists in the UK has been more and more prevalent in recent months. Reports of hundreds of people queuoutside local practices offering NHS dentistry seem to be worryingly frequent.

This is one sight that the people of Oldham in North-West England hopefully might never see, thanks to a pioneering idea that could ease the workload on NHS dentists in the area.

Oldham's dental nurse cadet scheme, which has been running since 2004, is modelled on the medical nurse cadet scheme. It sees cadets spending 12 weeks at The Oldham College, and then four days each week

in surgeries to learn

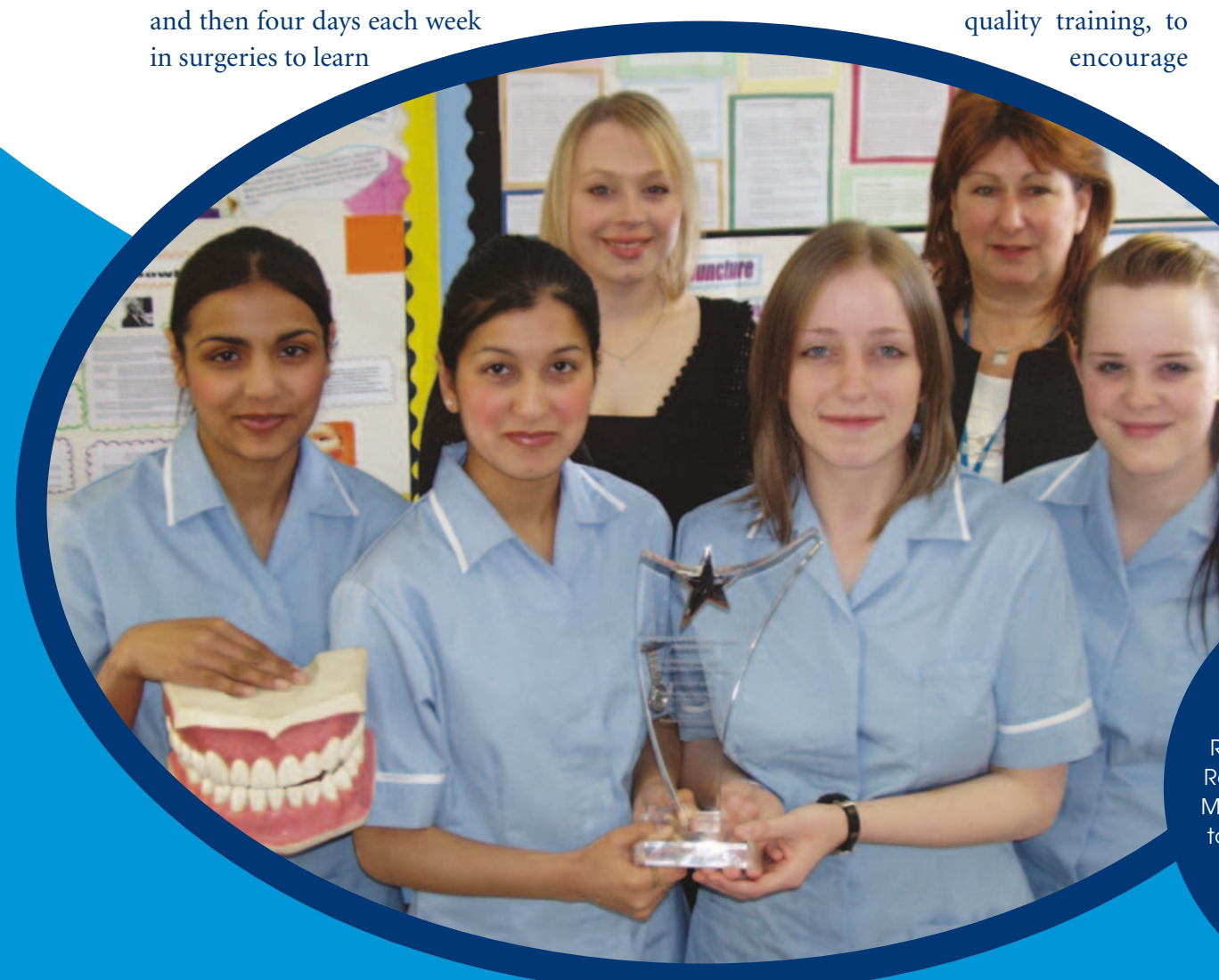

by a dentist's side. The scheme builds on experience and work with the bilingual dental nurse trainee scheme in Oldham.

The scheme is the brainchild of Oldham's consultant in dental public health Colette Bridgman, who developed the scheme with Donna Hough from the Workforce Confederation and Tony Spencer from The Oldham College.

It is part of a national push to bring more dentists to the NHS and to enable dental teams to deliver aspects of dentistry traditionally carried out by dentists.

Colette explains, 'I thought the nurse scheme was a great example of forward thinking. The idea of the scheme is to provide high quality training, to 


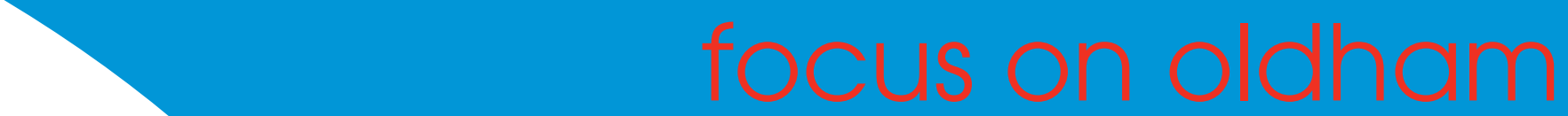

challenge. Other challenges faced were this age group of school leavers becoming employable in a matter of weeks. It is time-consuming working with two organisations in different sectors - education and health. Both had different approaches to finance and human resources issues and co-ordinating 15 dental practices and their staff to become familiar with the learning framework in colleges was a new area for all.'

\section{'We hope the scheme will be}

a great example to other NHS

\section{trusts of what can} be achieved.'

However, despite its teething difficulties, the scheme has had a resounding thumbs-up from cadets and practices alike. 'Feedback is exceptionally positive from the cadets who have remained on the scheme or who are now employed in dentistry, Colette reports. 'Having protected learning time within normal working hours is greatly appreciated, especially when they come into contact with peers who face evening classes after busy days in surgery.'
Practices have been
tremely pleased with the cadet scheme in operation; recruitment of dental nurses in Oldham has been addressed; and most of the cadets have moved to employment status in this first pilot so $100 \%$ employment is predicted.

The scheme is set to go from strength to strength, as following this initial pilot year, the PCT, the College and local practitioners want it to continue and are recruiting to the second cohort. There is steady interest from neighbouring PCTs to join the scheme and five places in the second cohort will have placements in a neighbouring PCT's practices.

It has even won a major accolade this year, beating 54 other nominees in its category to scoop an award in the positive performance section of the 2006 Greater Manchester NHS awards.

It was up against tough competition across various areas of health, and the aim was to recognise teams working in local health and social care organisations, who have really made a difference to the lives of the people they care for. The team who co-ordinated the scheme had to show they had led a development which has had a positive impact on the overall performance of a service or organisation.

What's happening in your PCT?

Is your surgery involved with any special events or schemes, or been rewarded for innovation?

If you are interested in being featured in a Focus on, contact

Arveen Bajaj on a.bajaj@nature.com or telephone 02078433679.

Richards,

Oldham PCT's

chief executive says, 'I am so pleased that the scheme has won. All those involved have worked so hard to make a difference to the hope the scheme will be a great example to other NHS trusts of what can be achieved.' 